\title{
Differential Expression of EGFR-1, MMP-3, and MMP-9 in Spontaneous Abortions, Induced Abortions, and Tubal Pregnancies
}

\author{
Mahi BALCI iD, Gülhan ÖZDEMir iD \\ Department of Pathology, Kırıkkale University Faculty of Medicine, KIRIKKALE, TURKEY
}

\begin{abstract}
Objective: The purpose of our study was to assess trophoblastic and uterine sufficiency in miscarriage pathogenesis with immunohistochemical methods and to determine if they could be used as a screening tool for the risk of miscarriage in the future.
\end{abstract}

Material and Method: Placental tissue specimens that were comprised of 20 spontaneous abortions, 23 voluntarily terminated (induced) abortions, and 12 tubal pregnancies were included in this study. Trophoblastic cells and implantation area were evaluated for staining with EGFR-1, MMP-3, and MMP-9 by immunohistochemistry.

Results: EGFR-1 expression was more intense and diffuse in decidual cells in the placental bed of spontaneous abortion specimens; this difference was statistically significant $(\mathrm{P}=0.004)$. MMP-3 expression was markedly increased in villous and extravillous trophoblastic cells in induced abortions; the difference between the groups was found to be statistically significant ( $\mathrm{P}$ values ranged from $<0.01$ to 0.005 ). MMP-9 expression tended to be higher in spontaneous abortion and tubal pregnancy specimens, and the results were statistically significant as $\mathrm{P}$ values were lower than 0.01 .

Conclusion: Higher EGFR-1 expression in the decidual tissue of spontaneous abortion specimens suggests that EGFR-1 triggers the migration of extravillous trophoblasts, leading to their destructive invasion. Similarly, MMP-9 immunopositivity might be indicative of aggressive invasion contributing to spontaneous abortion pathogenesis. Relatively high levels of MMP-3 expression in induced abortion specimens used as a control group might be a predictor of successful implantation, whereas its decreased expression might be indicative of risk for pregnancy loss.

Key Words: Spontaneous abortion, Induced abortion, Epidermal growth factor receptor, Metalloproteinases, Tubal pregnancy

\section{INTRODUCTION}

Spontaneous abortion is defined as the rejection of an embryo or fetus weighing less than $500 \mathrm{~g}$ and conceptus material consisting of placenta and its supplements from the uterus before 20-22 weeks of pregnancy $(1,2)$. The incidence of abortion, the most common complication of pregnancy, is approximately $15 \%$ in clinically diagnosed pregnancies. Although chromosomal abnormalities are present in $50 \%$ of all spontaneous abortion materials, the percentage is as high as $70 \%$ in miscarriage specimens in the 6th week of gestation (1). Endocrine disorders, anatomical abnormalities, multiple gestations, antiphospholipid antibodies, and medications are among the other etiological factors of early pregnancy loss. However, the mechanism underlying abortion has not been precisely elucidated. In particular, an explanatory cause of recurrent pregnancy losses cannot be found in 60\%-70\% cases $(1,3-5)$.

(Turk Patoloji Derg 2019, 35:1-8)

Received : 13.01.2018 Accepted : 10.05.2018
Considerable effort has focused on the implantation step, a very complex process involving interaction between blastocyst and endometrium. In particular, matrix metalloproteinases (MMPs) and tissue inhibitors of metalloproteases (TIMPs) have been extensively studied for their roles. MMPs are a family of zinc-dependent proteolytic enzymes with 28 identified isoforms. Several studies showed that MMP-2 and MMP-9 were expressed at early stages of placentation and that they degrade collagen type IV and other basal membrane components (6-8). Specifically, MMP-2 is produced and secreted predominantly by extravillous trophoblasts during early stages of the first trimester with a peak between the 6th and 8th weeks. Similarly, the expression of MMP-9 was shown in villous cytotrophoblasts and, to a lesser extent, in extravillous trophoblasts at both the mRNA and protein levels (9-12). MMP-3 degrades fibronectin, laminins, and various types of collagen and proteoglycan core proteins.

Correspondence: Mahi BALCI

Kirıkkale University Faculty of Medicine,

Department of Pathology, KIRIKKALE, TURKEY

E-mail: mahibalci@gmail.com Phone: +90 5078397706 
Previous studies have demonstrated that MMP-3 is weakly expressed in the proximal proliferating layer and is downregulated during the early invasive period, which is followed by upregulation in the late invasive period $(10,13)$.

Human placental development is an example of organogenesis with a very rapid growth capacity, similar to that of malignant tumors. The placenta synthesizes and secretes hormones, growth factors and their receptors as well as proto-oncogenes needed in both the growth and differentiation stages. One of the highly detected growth hormones in the human placenta is the epidermal growth factor (EGF) and its receptor, EGFR-1. EGF is a potent epithelial mitogen responsible for trophoblastic proliferation and has a stimulating effect on trophoblastic invasion. EGFR-1 is produced by cells in the proximal portion of the trophoblastic cell column in the early period. In addition, its expression was reported in other endometrial tissues and glandular secretions (14-16).

We hypothesized that, in addition to embryonic genetic defects, implantation failure also plays an important role in the etiology of early pregnancy loss. The purpose of this study was to elucidate the decidua-trophoblast relationship in the early implantation stage and to assess the role of trophoblasts and decidual cells in miscarriage pathogenesis with immunohistochemical approaches.

\section{MATERIAL and METHODS}

Placental tissue specimens from 55 archival cases that were comprised of 20 spontaneous abortions, 23 induced abortions, and 12 tubal pregnancies were included in this study. Paraffin blocks of formalin fixed tissue specimens were collected from the archives of the Pathology Department at the Faculty of Medicine, Kirikkale University. The age of patients ranged from 20 to 26 , and none of the patients had evidence of psychological disorders. Suction curettage was performed before 13 weeks of pregnancy for both induced and spontaneous abortions. The time of surgical removal of ectopic growth materials varied between 14 and 16 weeks gestation.

\section{Immunohistochemistry}

For immunohistochemistry, $6-\mu \mathrm{m}$-thick sections that were mounted on glass slides coated with organosilane adhesive were stained using the streptavidin-biotin method. Briefly, histological sections were deparaffinized in xylene and rehydrated through a graded series of alcohol washes. After antigen retrieval, endogenous peroxidase activity was blocked with 3\% hydrogen peroxide incubation for $5 \mathrm{~min}$. After washes with distilled water, the slides were arranged in a Sequenza automatic slide stainer (Ventana, Benchmark
$\mathrm{XT}$ ), and phosphate-buffered saline (PBS) was used as the washing solution. After blocking in Ultra-V-Block protein blocking Reagent (Labvision, Fremont, CA, USA) for 5 $\mathrm{min}$, slides were incubated with primary antibodies against EGFR-1 (ab16671, diluted in 1/200), MMP-3 (ab77962, diluted in 1/100), and MMP-9 (ab51203, diluted in 1/200) at room temperature in a humidifier overnight. The slides were then washed with PBS, incubated with biotinylated secondary goat antibodies for $45 \mathrm{~min}$, and stained with diaminobenzidine (Thermo Fisher Scientific Anatomical Pathology, UK) as a chromogen for $20 \mathrm{~min}$. The slides were counterstained with Mayer's hematoxylin for $4 \mathrm{~min}$. Finally, the sections were dehydrated through a graded series of alcohol washes, cleared in xylene, and mounted in Entellan' (Merck, Kenilworth, NJ, USA). Placental tissue was used as a positive control, and PBS not containing primary antibodies was used as negative control.

\section{Assessment of Immunohistochemical Staining}

Villous and extravillous trophoblasts and placental bed in serial sections of the specimens were evaluated for staining with EGFR-1, MMP-3, and MMP-9. We used a semiquantitative scoring system to evaluate staining intensity and extent. Every slide was examined by two pathologists. Specifically, each evaluated area was given a score according to the intensity of nucleic or cytoplasmic staining (no staining, 0 ; weak staining, 1 ; moderate staining, 2; strong staining, 3) and the extent of stained cells ( $0 \%, 0 ;<33 \%, 1$; $34 \%-66 \%, 2 ;>66 \%, 3)$. The final immunoreactive score was determined by multiplying the intensity score with the score for extent of stained cells, to achieve a minimum score of 0 and a maximum score of 9 secretions (17). Accordingly, sum scores were categorized into three levels for statistical analysis: level 1, 1-3; level 2, 4-6; and level 3, 7-9.

\section{Statistical Analysis}

All statistical analyses were performed using the SPSS $15.0^{\circ}$ statistical software (SPSS Chicago, IL, USA). The Chi - square $\left(\chi^{2}\right)$ test was performed for comparison of the immunohistochemical expression levels between two groups. $\mathrm{P}$ values $<0.05$ were considered statistically significant with a confidence interval of $95 \%$.

\section{RESULTS}

The majority of cytotrophoblastic, syncytiotrophoblastic and extravillous trophoblastic cells showed level 3 EGFR-1 immunostaining in all three clinical groups. A statistically significant difference was detected between cytotrophoblasts of induced abortion and tubal pregnancy cases ( $\mathrm{p}=0.012$; Table I). A level 3 MMP-3 immunostaining was observed in cytotrophoblastic cells of 21 of a total 
of 23 induced abortion cases, which was much lower in spontaneous abortion and tubal pregnancy cases ( $<<0.01$ or equal to 0.001 ; (Table I) (Figure 1). Similarly, level 3 immunostaining was determined for MMP-3 in syncytiotrophoblastic cells in most induced abortion cases when compared with spontaneous abortions and tubal pregnancy $(\mathrm{p}<0.01)$ (Table II) (Figure 1). All spontaneous abortion and tubal pregnancy specimens had level 3 syncytiotrophoblastic MMP-9 expression, whereas the majority of spontaneous abortion cases displayed level 2 MMP-9 immunostaining ( $\mathrm{p}<0.01)$ (Table II). In extravillous trophoblasts, all spontaneous abortions and tubal pregnancy specimens showed level 3 MMP-9

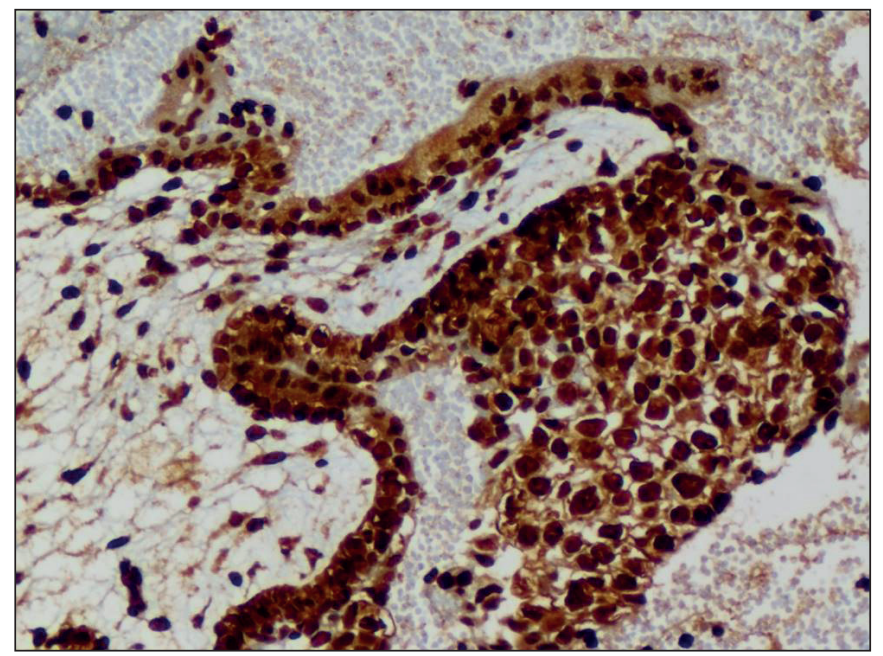

Figure 1: Intense and diffuse nuclear MMP-3 expression in villous and some extravillous trophoblasts in induced abortion (IHC; x200).

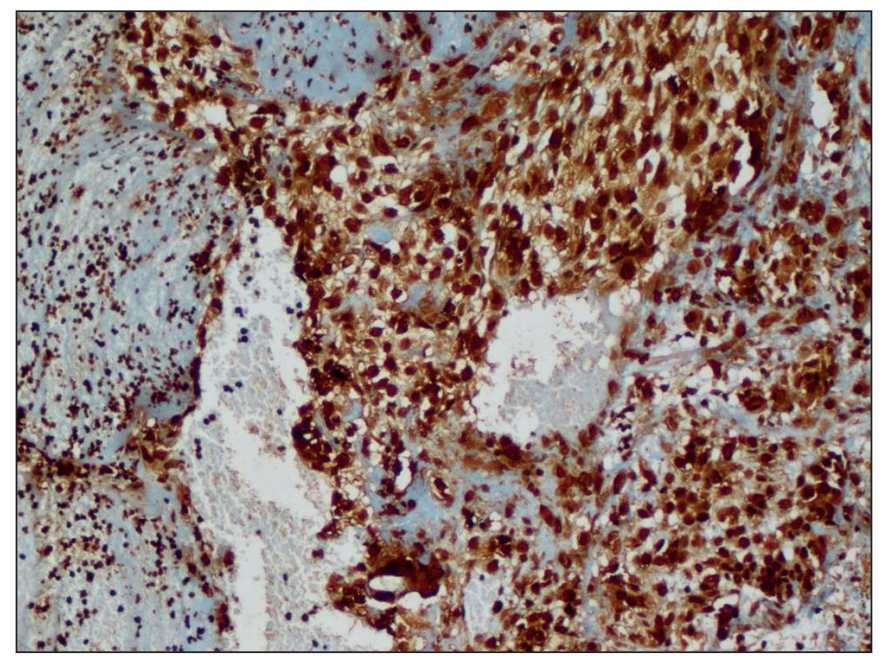

Figure 3: Diffuse and intense immunoreaction with MMP-9 in extravillous trophoblasts in ectopic pregnancy (IHC; x100). immunoreactivity while moderate or weak nuclear staining was observed in induced abortions $(\mathrm{p}<0.01)$ (Table III) (Figure 2,3).

The expression of EGFR-1, MMP-3, and MMP-9 was evaluated only in spontaneous and induced abortion specimens as a decidual reaction is minimally observed in tubal pregnancy. The results demonstrated that significantly more spontaneous abortion cases exhibited level 3 EGFR1 expression in decidual cells of the implantation area, compared with induced abortions $(\mathrm{p}=0.004)$ (Table IV) (Figure 4). There was also a significant difference between MMP-3 and MMP-9 expressions among corresponding groups ( $\mathrm{p}=0.003$ and $\mathrm{p}<0.01$, respectively) (Table IV).

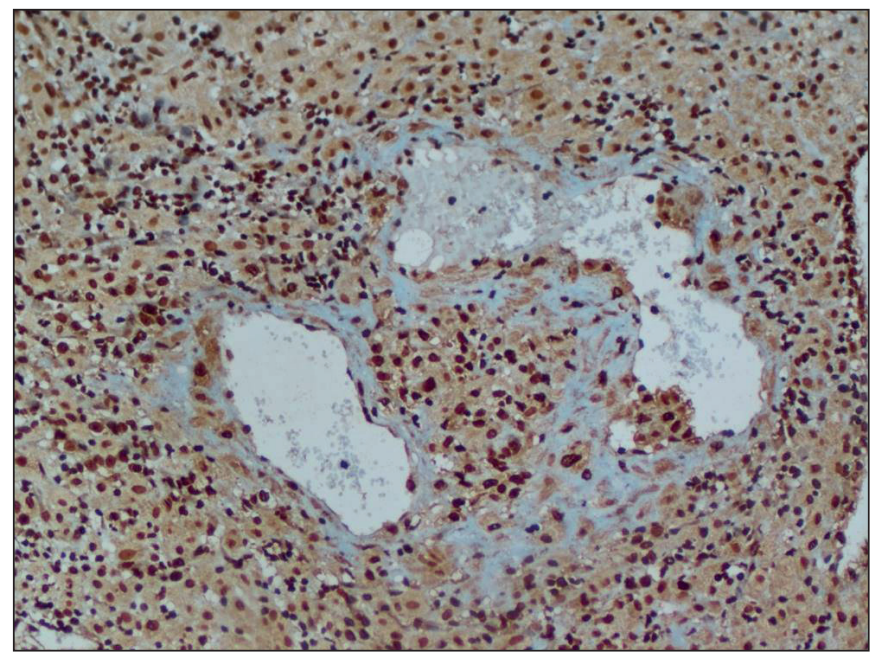

Figure 2: Diffuse and strong MMP-9 positivity in extravillous trophoblasts with atypical nuclear features in the vascular lumen and stroma in spontaneous abortion (IHC; x100).

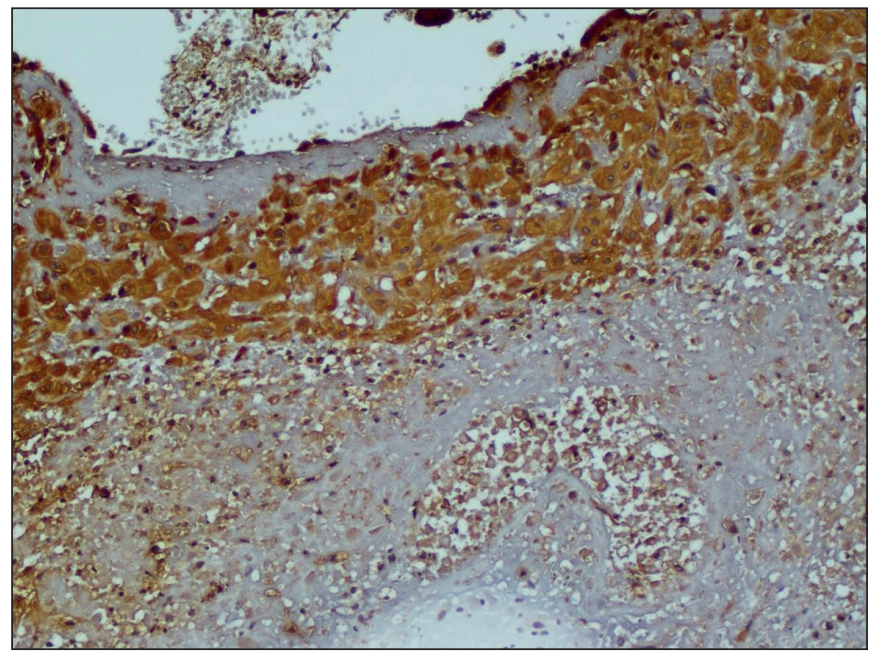

Figure 4: Strong cytoplasmic EGFR-1 positivity in implantation site decidual cells in spontaneous abortion (IHC; x200). 
Table I: The sum value of the EGFR-1, MMP-3, MMP-9, positivity in cytotrophoblasts between the groups (n)

\begin{tabular}{|c|c|c|c|c|c|c|c|}
\hline & \multicolumn{2}{|c|}{ EGFR-1 } & \multicolumn{3}{|c|}{ MMP-3 } & \multicolumn{2}{|c|}{ MMP-9 } \\
\hline & Level 2 & Level 3 & Level 1 & Level 2 & Level 3 & Level 2 & Level 3 \\
\hline Spontaneous Abortion $(n=20)$ & 1 & 19 & 2 & 11 & 7 & 0 & 20 \\
\hline Induced Abortion $(n=23)$ & 0 & 23 & 0 & 2 & 21 & 1 & 22 \\
\hline Tubal Pregnancy $(\mathrm{n}=12)$ & 3 & 9 & 1 & 8 & 3 & 0 & 12 \\
\hline P Value & $\begin{array}{l}\text { Induced } \\
\text { Tubal Pre }\end{array}$ & $\begin{array}{l}\text { rtion } v s \\
c y=0,012\end{array}$ & $\begin{array}{l}\text { Spontane } \\
\text { Induced Al }\end{array}$ & $\begin{array}{l}\text { Induced } \\
\text { vs Tuba }\end{array}$ & $\begin{array}{l}\text { on }=0,001 \\
\text { ancy }<0,01\end{array}$ & & 05 \\
\hline
\end{tabular}

Table II: The sum value of the EGFR-1, MMP-3, MMP-9, positivity in syncytiotrophoblasts between the groups (n)

\begin{tabular}{lcccccccc}
\hline & EGFR-1 & \multicolumn{1}{c}{ MMP-3 } & \multicolumn{2}{c}{ MMP-9 } \\
\hline & Level 2 & Level 3 & Level 1 & Level 2 & Level 3 & Level 1 & Level 2 & Level 3 \\
\hline Spontaneous Abortion $(\mathrm{n}=20)$ & 0 & 20 & 1 & 13 & 6 & 0 & 0 & 20 \\
\hline Induced Abortion $(\mathrm{n}=23)$ & 0 & 23 & 0 & 1 & 22 & 4 & 17 & 2 \\
\hline Tubal Pregnancy $(\mathrm{n}=12)$ & 1 & 11 & 1 & 8 & 3 & 0 & 0 & 12 \\
\hline P Value & $>0,05$ & $\begin{array}{c}\text { Spontaneous vs Induced Abortion } \\
<0,01 \text { Induced Abor tion vs Tubal } \\
\text { Pregnancy<0,01 }\end{array}$ & $\begin{array}{c}\text { Spontaneous vs Induced Abortion } \\
<0,01 \text { Induced Abor tion vs Tubal } \\
\text { Pregnancy<0,01 }\end{array}$ \\
\hline
\end{tabular}

Table III: The sum value of the EGFR-1, MMP-3, MMP-9, positivity in extravillous trophoblasts between the groups (n)

\begin{tabular}{|c|c|c|c|c|c|c|c|c|}
\hline & \multicolumn{2}{|c|}{ EGFR-1 } & \multicolumn{3}{|c|}{ MMP-3 } & \multicolumn{3}{|c|}{ MMP-9 } \\
\hline & Level 2 & Level 3 & Level 1 & Level 2 & Level 3 & Level 1 & Level 2 & Level 3 \\
\hline Spontaneous Abortion $(\mathrm{n}=20)$ & 1 & 19 & 1 & 11 & 8 & 0 & 0 & 20 \\
\hline Induced Abortion $(\mathrm{n}=23)$ & 6 & 17 & 0 & 3 & 20 & 7 & 11 & 5 \\
\hline Tubal Pregnancy $(\mathrm{n}=12)$ & 1 & 11 & 1 & 6 & 5 & 0 & 0 & 12 \\
\hline P Value & \multicolumn{2}{|c|}{$>0,05$} & \multicolumn{3}{|c|}{$\begin{array}{c}\text { Spontaneous vs Induced Abortion } \\
=0,005 \text { Induced Abor tion vs Tubal } \\
\text { Pregnancy }=0,015\end{array}$} & \multicolumn{3}{|c|}{$\begin{array}{c}\text { Spontaneous vs Induced Abortion } \\
<0,01 \text { Induced Abor tion vs Tubal } \\
\text { Pregnancy }<0,01\end{array}$} \\
\hline
\end{tabular}

Table IV: The sum value of the EGFR-1, MMP-3, MMP-9, positivity in implantation area desidual cells between the groups (n)

\begin{tabular}{lcccccccc}
\hline & \multicolumn{2}{c}{ EGFR-1 } & \multicolumn{1}{c}{ MMP-3 } & \multicolumn{2}{c}{ MMP-9 } \\
\hline & Level 2 & Level 3 & Level 1 & Level 2 & Level 3 & Level 1 & Level 2 & Level 3 \\
\hline Sponta neous Abortion $(\mathrm{n}=20)$ & 7 & 13 & 10 & 9 & 1 & 0 & 1 & 19 \\
\hline Induced Abortion $(\mathrm{n}=23)$ & 18 & 5 & 1 & 19 & 3 & 1 & 20 & 2 \\
\hline \multirow{2}{*}{ P Value } & Spontaneous vs Induced & Spontaneous vs Induced & Spontaneous vs Induced \\
& Abortion $=0,004$ & \multicolumn{3}{c}{ Abortion $=0,003$} & Abortion $<0,01$ \\
\hline
\end{tabular}

\section{DISCUSSION}

The adherence of competent blastocyst on the receptive endometrium includes a complex and tightly regulated process of mutual signaling where maternal-fetal dialogue is established. Further, successful implantation requires an optimally maturated decidua, well developed capillary plexus, and adequate glandular development prior to implantation. Of these, functional decidualization is essential for pregnancy to regulate maternal immune tolerance and facilitate placentation $(18,19)$. During implantation and placentation, a variety of growth factors, adhesion molecules, proto-oncogenes, cytokines, and proteases play active roles in remodeling of the endometrium, trophoblast invasion, proliferation, and differentiation $(6,13,18-20)$. 
In this study, we showed intense and diffuse EGFR-1 expression in both villous and extravillous trophoblasts in all clinical groups. However, the rate of cases displaying strong and diffuse EGFR-1 expression in decidual cells of implantation area was higher in spontaneous abortions than induced abortions. Our findings suggested that the number of EGFR-1 receptors in the placental bed might be upregulated to compensate for invasion of stimulated trophoblasts. Conversely, EGFR-1 in decidual cells might exhibit an overexpressed mutant type that is the result of molecular defects affecting DNA in spontaneous abortion cases, which warrants future molecular analysis. Large et al. demonstrated that the coordinate actions of EGFR are critical for the successful progression of early pregnancy. They identified over 3,000 misregulated genes in the absence of EGFR. Bioinformatics analysis revealed widespread alterations including genes involved in growth factor and kinase signaling, the cell cycle, DNA replication, and cell survival (20). Wright et al. found that the expression of $\alpha_{1}$ and $\alpha_{6}$-adhesion molecules which are essential for invasion or interaction with the extracellular matrix were decreased in the extravillous trophoblastic cell line by blocking epidermal growth factor receptor (EGFR/HER1) activation (21). In contrast, EGFR is overexpressed in approximately $50 \%$ of endometrial tumors and is significantly associated with decreased survival in patients with Type II endometrial cancer $(22,23)$.

Increased level of EGFR-1 expression observed in decidua of spontaneous abortions in our study could be interpreted as exaggerated decidualization. We suggest that this aberrant decidual phenotype would respond paradoxically to embryonic HCG stimuli. In addition, EGF might reduce maternal immune tolerance. EGFR1 has a number of ligands including EGF, transforming growth factor (TGF- $\alpha$ ), heparin-binding (HB)-EGF, amphiregulin, betacellulin, and epiregulin; many inflammatory cells, such as eosinophils, neutrophils, mast cells, and macrophages can produce these ligands. EGFR activation leads to cell migration, proliferation, and upregulation of cytokines modulating innate immune system $(24,25)$. Successful reproduction relies on limited inflammation during implantation, anti-inflammation during the mid-pregnancy, and inflammation again during parturition. Uterine natural killer cells (NK) and regulatory $\mathrm{T}$ cells (Tregs) are abundant during the early stages of pregnancy. NK cells and Tregs have supposed to undergo numerical or functional changes in patients with a history of spontaneous abortion, implantation failure or other pregnancy complications. Tregs acquire an inflammatory phenotype and produce inflammatory cytokines instead of immunosuppressive IL-10 and TGF- $\beta$ (26-28).
Numerous findings have suggested that a substantial portion of the effects attributed to EGFR antagonist treatment in cancer might not be based on direct influence on the tumour itself. Instead it may be based on indirect effects, potentially mediated via the immune system. EGFR antagonist treatment could be impacting tumor growth by blocking macrophage and regulatory $\mathrm{CD} 4+\mathrm{T}$ cell function (29).

Disruption of balance between activating and inhibiting regulatory factors controlling immunity in the implantation might lead to the accumulation of potential cytotoxic decidual macrophages and Tregs that trigger immune mediated pregnancy loss. However, further research will be needed to clarify the relationship between EGF and immune tolerance.

In this study, we evaluated the invasive capability of trophoblasts, an important step of implantation, extracellular matrix degradation, and remodeling of the matrix by MMPs secreted by these cells. MMP- 2 and MMP9 play key roles in the destruction of matrix components and were extensively studied in the context of early implantation. However, there are a limited number of well controlled studies on recurrent pregnancies or spontaneous abortions, with conflicting results. For example, while some studies determined that the expression of MMPs and their tissue inhibitors were increased in recurrent miscarriages, others reported decreased levels of these factors. The distribution of MMP-3 and MMP-9 expression in our study differed between different clinical groups. The expression of MMP3 tended to be higher in induced abortion cases, whereas MMP-9 exhibited evident immunopositivity in specimens from spontaneous abortions and tubal pregnancies.

In an in vivo model of induced abortion, where Kanca et al. inhibited pregnancy at mid-gestation with a progesterone receptor antagonist in ten domestic animals, MMP-2 and MMP-9 activity were evaluated (30). They also included seven animals with normal pregnancy as the control group and five spontaneous abortion cases. They determined that MMP-2 and MMP 9 expression in induced abortion specimens were lower than those in spontaneous abortion cases, with lowest expression in the control group. These findings were consistent with the results of our study. Similarly, an immunohistochemical study of MMP-9 and TIMP-3 conducted by Liu et al. compared 30 spontaneous abortion cases with 20 normal pregnancies. In cases of spontaneous abortion, they detected that MMP-9 expression was higher in the decidua from spontaneous abortions than that of normal pregnancies. In addition, they did not detect a difference in TIMP expression between clinical groups, which was similar to that observed 
in controls. They concluded that an increased ratio of MMP-9/TIMP-3 might trigger spontaneous abortion (31). Nissi et al. assessed serum levels of MMP-2, MMP9, and their tissue inhibitors in 40 normal pregnancies and 89 spontaneous abortions. The authors found that serum MMP-9 and MMP-2/TIMP-2 ratio were elevated in spontaneous abortions, whereas tissue inhibitors were at lower levels in normal pregnancy cases (32). Sundrani et al. reported higher mRNA levels of MMP-1, -2 and -9 in the placentae of those delivering preterm as compared to term labor. Additionally, MMP-9 gene promoter was hypomethylated in preterm placentas compared to term placenta in this study (33).

It has been shown that placental leukocytes from human term pregnancies are able to secrete large amounts of MMP9 , and that the production of the enzyme is enhanced by labor. The authors demonstrated that endogenous MMP-3 plays a major role in the MMP-9 activation process (34). These findings are in accordance with our suggestion that inflammation may contribute to creating the collagenolytic microenvironment that induces miscarriage like term labor. Some studies have focused on genotype analysis of matrix metalloproteinases including the MMP-9 gene polymorphism but found no significant differences between spontaneous abortion or other placental disorders and control groups $(35,36)$.

The role of MMPs was previously investigated in tubal pregnancy materials as well. Since there is no decidualization in tubal mucosa, Neratzoula and Judith reported that trophoblasts could exhibit a highly invasive phenotype in tubal pregnancy $(37,38)$. A study on unruptured tubal pregnancy specimens by Qui et al. suggested that the levels of MMPs were significantly increased in the ectopic implantation site and that the expression of tissue inhibitors of MMPs were decreased. They concluded that dysregulation of the balance between MMPs and their tissue inhibitors could result in widespread and severe destruction of extracellular matrix in ectopic implantation (39). Both the mRNA level and immunoreactivity of MMP9, TIMP-1 and -3 has found to be increased, while those of TIMP-2 decreased concurrent with the progression of pregnancy during weeks 3-9 in tubal pregnancy (40).

The data obtained from these studies investigating MMPs to understand implantation, remodeling, and placentation showed that MMP-9 played a more important role than other MMPs and that invasion could not occur without MMP-9 in vitro.
The findings in our study suggested that increased MMP-9 expression in spontaneous abortion and tubal pregnancy might result from an exaggerated, uncontrolled trophoblastic invasion as part of the miscarriage pathogenesis. In addition, increased EGFR-1 expression in decidual cells of spontaneous abortion cases suggested that EGFR-1 might stimulate the migration of extravillous trophoblasts, leading to destructive invasion. Overall, these findings indicated that aggressive invasion, might play a role in spontaneous abortion pathogenesis.

We detected relatively moderate MMP-3 expression in spontaneous abortion specimens compared to other groups, which suggests that there is an inverse correlation between MMP-3 and MMP-9. The presence of relatively high MMP-3 expression in induced abortion cases that comprised the control group in this study might be a predictor of successful implantation. Consequently, decreased MMP-3 level might be indicative of increased risk for pregnancy loss. Future comparative studies are needed to determine if serum MMP levels could be utilized to assess pregnancy progression and to prevent unwanted abortions via screening.

\section{ACKNOWLEDGEMENTS}

We thank Dr. Mustafa Emre Ercin and Dr. Selçuk Yıldız for providing assistance in data collection and statistical analysis.

\section{CONFLICT of INTEREST}

The authors declare no conflict of interest.

\section{FINANCIAL DISCLOSURE}

Our study was financially supported by Kirikkale University Research Project Unit. The Project number: 2012-80.

\section{REFERENCES}

1. Benirschke K, Kaufmann P, Baergen RN. Pathology of the human placenta. 6th ed. New York: Springer; 2012.

2. Regan L, Rai R. Epidemiology and the medical causes of miscarriage. Baillieres Best Pract Res Clin Obstet Gynaecol. 2000;14:839-54.

3. García-Enguídanos A, Calle ME, Valero J, Luna S, DomínguezRojas V. Risk factors in miscarriage: A review. Eur J Obstet Gynecol Reprod Biol. 2002;102:111-9.

4. Rai R, Regan L. Recurrent miscarriage. Lancet 2006;368:601-11.

5. Carrell DT, Peterson M. Reproductive endocrinology and infertility. Newyork: Springer; 2010.

6. Salomonsen LA. Role of proteases in implantation. Rev Reprod. 1999;4:11-2. 
7. Polette M, Nawrocki B, Pintiaux A, et al. Expression of gelatinases $\mathrm{A}$ and $\mathrm{B}$ and the tissue inhibitors by cells of early and term hamun placenta and gestational endometrium. Labor Invest. 1994;71:838-46.

8. Staun-Ram E, Goldman S, Shalev E. p53 Mediates epidermal growth factor (EGF) induction of MMP-2 transcription and trophoblast invasion. Placenta. 2009;30:1029-36.

9. Zhu JY, Pang ZJ, Yu YH. Regulation of Trophoblast Invasion: The Role of Matrix Metalloproteinases. Rev Obstet Gynecol 2012; 5:e137-43.

10. Huppertz B, Kertschanska S, Demir AY, Frank HG, Kaufmann P. Immunohistochemistry of matrix metalloproteinases (MMP), their substrates, and their inhibitors (TIMP) during trophoblast invasion in the human placenta. Cell Tissue Res. 1998;291:13348.

11. Xu P, Wang YL, Zhu SJ, Luo SY, Piao YS, Zhuang LZ. Expression of matrix metalloproteinase-2, -9, and -14, tissue inhibitors of metalloproteinase-1, and matrix proteins in human placenta during the first trimester. Biol Reprod. 2000;62:988-94

12. Bischof P, Meisser A, Campana A. Control of MMP-9 expression at the maternal-fetal interface. J Reprod Immunol. 2002;55:3-10.

13. Cohen M, Meisser A, Bischof P. Metalloproteinases and human placental invasiveness. Placenta. 2006;27:783-93.

14. Mühlhauser J, Crescimanno C, Kaufmann P, Höfler H, Zaccheo D, Castellucci M. Differentiation and proliferation patterns in human trophoblast revealed by c-erbB-2 oncogene product and EGF-R. J Histochem Cytochem. 1995;43:579-89.

15. Jokhi PP, King A, Loke YW. Reciprocal expression of epidermal growth factor receptor (EGF-R) and c-erbB2 by non-invasive and invasive human trophoblast populations. Cytokine. 1994;6:43342.

16. Maruo T, Matsuo H, Otani T, Mochizuki M. Role of epidermal growth factor (EGF) and its receptor in the development of the human placenta. Reprod Fertil Dev. 1995;7:1465-70.

17. Abdelrahman AE, Arafa SA, Ahmed RA. Prognostic value of twist-1, E-cadherin and EZH2 in prostate cancer: An immunohistochemical study. Turk Patoloji Derg. 2017;33:198210.

18. Cartwright JE, Fraser R, Leslie K, Wallace AE, James JL. Remodelling at the maternal-fetal interface: relevance to human pregnancy disorders. Reproduction. 2010;140:803-24.

19. Salker M, Teklenburg G, Molokhia M, et al. Natural selection of human embryos: Impaired decidualization of endometrium disables embryo-maternal interactions and causes recurrent pregnancy loss. PLoS One. 2010;5:e10287.

20. Large MJ, Wetendorf M, Lanz RB, Hartig SM, Creighton CJ, Mancini MA, Kovanci E, Lee KF, Threadgill DW, Lydon JP, Jeong JW, DeMayo FJ. The epidermal growth factor receptor critically regulates endometrial function during early pregnancy. PLoS Genet. 2014;10:e1004451.

21. Wright JK, Dunk CE, Amsalem H, Maxwell C, Keating S, Lye SJ. HER1 signaling mediates extravillous trophoblast differentiation in humans. Biol Reprod. 2010;83:1036-45.
22. Reyes HD, Thiel KW, Carlson MJ, Meng X, Yang S, Stephan JM, Leslie KK. Comprehensive profiling of EGFR/HER receptors for personalized treatment of gynecologic cancers. Mol Diagn Ther. 2014;18:137-51.

23. Konecny GE, Santos L, Winterhoff B, Hatmal M, Keeney GL, Mariani A, Jones M, Neuper C, Thomas B, Muderspach L, Riehle D, Wang HJ, Dowdy S, Podratz KC, Press MF. HER2 gene amplification and EGFR expression in a large cohort of surgically staged patients with nonendometrioid (type II) endometrial cancer. Br J Cancer. 2009;100:89-95.

24. Moffett-King A. Natural killer cells and pregnancy. Nat Rev Immunol. 2002;2:656-63.

25. Tabiasco J, Rabot M, Aguerre-Girr M, El Costa H, Berrebi A, Parant O, Laskarin G, Juretic K, Bensussan A, Rukavina D, Le Bouteiller P. Human decidual NK cells: Unique phenotype and functional properties-a review. Placenta 2006;27: S34-9.

26. Surendra S. Natural killer cells and regulatory $\mathrm{T}$ cells in early pregnancy loss. Int J Dev Biol. 2014;58:219-29.

27. Doisne JM, Balmas E, Boulenouar S, Gaynor LM, Kieckbusch J, Gardner L, Hawkes DA, Barbara CF, Sharkey AM, Brady HJ, Brosens JJ, Moffett A, Colucci F. Composition, development, and function of uterine innate lymphoid cells. J Immunol. 2015;195:3937-45.

28. Wallace AE, Fraser R, Cartwright JE. Extravillous trophoblast and decidual natural killer cells: A remodelling partnership. Hum Reprod Update. 2012;18:458-71.

29. MacDonald F, Zaiss DMW. The immune system's contribution to the clinical efficacy of EGFR antagonist treatment. Front Pharmacol. 2017;8:575.

30. Kanca H, Walter I, Miller I, Schäfer-Somi S, Izgur H, Aslan S. Expression and activity of matrix metalloproteinases in the uterus of bitches after spontaneous and induced abortion. Reprod Domest Anim. 2011;46:197-204.

31. Liu C, Gao Y, Guo Y. Relationship between the matrix metalloproteinase-9/tissue inhibitor of metalloproteinase-3 in decidua tissue and spontaneous abortion. J Clin Exp Pathol. 2004;20:551-3.

32. Nissi R, Talvensaari-Mattila A, Kotila V, Niinimäki M, Järvelä I, Turpeenniemi-Hujanen T. Circulating matrix metalloproteinase MMP-9 and MMP-2/TIMP-2 complex are associated with spontaneous early pregnancy failure. Reprod Biol Endocrinol. 2013;11:2.

33. Sundrani DP, Chavan-Gautam PM, Pisal HR, Mehendale SS, Joshi SR. Matrix metalloproteinase-1 and -9 in human placenta during spontaneous vaginal delivery and caesarean sectioning in preterm pregnancy. PLoS One. 2012;7:e29855.

34. Flores-Pliego A, Espejel-Nuñez A, Castillo-Castrejon M, MerazCruz N, Beltran-Montoya J, Zaga-Clavellina V, Nava-Salazar S, Sanchez-Martinez M, Vadillo-Ortega F, Estrada-Gutierrez G. Matrix Metalloproteinase-3 (MMP-3) is an endogenous activator of the MMP-9 secreted by placental leukocytes: Implication in human labor. PLoS One. 2015;10:e0145366.

35. Barišić A, Dević Pavlić S, Ostojić S. Matrix metalloproteinase and tissue inhibitors of metalloproteinases gene polymorphisms in disorders that influence fertility and pregnancy complications: A systematic review and meta-analysis. Gene. 2018 Mar 20;647:4860 
36. Ramu D, Venkatesan V, Paul SFD. Genetic variation in matrix metalloproteinase MMP2 and MMP9 as a risk factor for idiopathic recurrent spontaneous abortions in an Indian population. J Assist Reprod Genet. 2017;34:945-9.

37. Neratzoula V, Judith NB. Characterization of tubal and decidual leukocyte populations in ectopic pregnancy: Evidence that endometrial granulated lymphocytes are absent from the tubal implantation site. Fertil Steril. 1998;69:760-7.
38. Marx L, ArckP, Kapp M, Kieslich C, Dietl J.Leukocyte populations, hormone receptors and apoptosis in eutopic and ectopic first trimester human pregnancies. Human Reprod.1999;14:1111-7.

39. Qiu X, Xie Y, Chen L, Gemzell-Danielsson K. Expression of matrix metalloproteinases and their inhibitors at the fetomaternal interface in unruptured ectopic tubal pregnancy. Acta Obstet Gynecol Scand. 2011;90:966-71.

40. Bai SX, Wang YL, Qin L. Dynamic expression of matrix metalloproteinases (MMP-2, -9 and 14) and the tissue inhibitors of MMPs (TIMP-1, -2 and -3 ) at the implantation site during tubal pregnancy. Reproduction. 2005;129:103-13. 